Seminar Nasional Teknologi Informasi dan Kedirgantaraan (SENATIK)

Vol. III, 21 Desember 2017, P-ISSN: 2337-3881, E-ISSN: 2528-1666

DOI: http://dx.doi.org/10.28989/senatik.v3i0.114

\title{
PEMETAAN GROUND ACCELERATION MENGGUNAKAN METODE PROBABILISTIC SEISMIC HAZARD ANALYSIS DI PROPINSI NUSA TENGGARA BARATPADA ZONA MEGATHRUST
}

\author{
Riski Kurniawan \\ Sekolah Tinggi Teknologi Adisutjipto \\ Jl. Janti Blok. R, Lanud Adisutjipto Yogyakarta \\ Email : riskikur110@gmail.com
}

\begin{abstract}
This study aims to map disaster-prone areas of earthquake disaster in NTB Province using PSILA method to obtain a peak ground acceleration probability map periodically based on the latest earthquake data in megathrust zone and background zone as one of earthquake disaster mitigation efforts. This research is based on earthquake occurrence data in NTB Province and surrounding area for 116 years which processed using software Ez-Frisk 7.52. The framework using the PSHA method starts from the phase of collecting the earthquake data for 116 years at coordinates of $-6.33^{\circ} \mathrm{LS}$ to $-11.33^{\circ} \mathrm{LS}$ and $112.45^{\circ}$ east to $119.83^{\circ}$ east obtained from the USGS, ISC and ANSS earthquake catalogs. Next, convert the magnitude into the magnitude scale of the moment before the earthquake identification using Gardner and Knopoof criteria to obtain the a-b parameter. The determination of attenuation function based on earthquake source modeling is determined by the researcher, ie the source of earthquake interface subduction (megathrust) earthquake and the source of earthquake intraslab subduction (deep background). The calculation of peak ground acceleration values uses the basic probability theory developed by Cornell. The result of spectral acceleration due to the source of subduction earthquake in West Nusa Tenggara Province based on probabilistic analysis ranges from $0.04 \mathrm{~g}-0.1 \mathrm{~g}$ for the re-period of 500 years, while for the 2500 year reperiod is $0.08 \mathrm{~g}-0.3 \mathrm{~g}$. For shallow background the earthquake ranges from $0.1 \mathrm{~g}-0.3 \mathrm{~g}$ for the re-period of 500 years, while for the 2500 year re-period is $0.2 \mathrm{~g}-0.5 \mathrm{~g}$. While for the source of deep background earthquakes ranged from $0.2 \mathrm{~g}-0.3 \mathrm{~g}$ for the re-period of 500 years, while for the 2500 year re-period is $0.3 \mathrm{~g}-0.4 \mathrm{~g}$.
\end{abstract}

Keywords: PSHA, subduction, interface, intraslab, background, acceleration.

1. Pendahuluan

Gempa bumi terjadi di daerah pertemuan antara lempeng benua dan samudra. Secara geografis, Indonesia terletak pada pertemuan tiga lempeng besar dunia, yaitu Lempeng Indo-Australia di bagian selatan, Lempeng Pasifik di bagian timur, dan lempeng Eurasian di bagian utara. Pertemuan tiga lempeng besar dan sembilan lempeng kecil mengakibatkan terbentuknya daerah penunjaman atau subduksi (subduction zone) sehingga menjadikan Indonesia berada pada zona tektonik aktif [4].

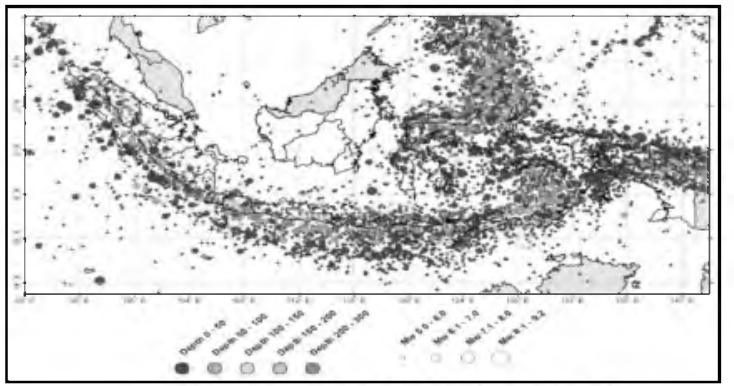

Gambar 1.1 Episenter di

Indonesia untuk magnitude $>5.0$ tahun 1900-2009. [7]

Salah satu wilayah di Indonesia yang memiliki tingkat kerawanan gempabumi tinggi adalah Propinsi NTB. Secara tektonik, busur kepulauan Nusa Tenggara berada di antara zona tumbukan lempeng samudera Indo-Australia dengan Eurasia di bagian selatan (zona subduksi) dan patahan 
naik busur belakang (back arc trust) BaliFlores di bagian utara. Zona penunjaman terjadi sebagai akibat aktifitas lempeng Samudera Indo - Australia yang bergerak mendekati lempeng benua Eurasia dengan kecepatan kurang lebih $7 \mathrm{~cm} /$ tahun [9].

Efek dari gempabumi dapat mempengaruhi keselamatan jiwa dan bangunan.Berdasarkan fakta tersebut, penulis melakukan penelitian dengan memetakan kawasan rawan resiko bencana gempabumi di Propinsi NTB menggunakan metode PSHA untuk mendapatkan peta probabilitas peak ground acceleration secara periodik berdasarkan data gempa terbaru di zona megathrust dan backgroundsebagai salah satu upaya mitigasi bencana gempabumi.

Analisis PSHA pada penelitian ini ini diharapkan dapat memberikan informasi yang lebih komunikatif bagi masyarakat untuk menentukan wilayah rawan bencana gempabumi. Langkah ini merupakan upaya mitigasi awal untuk meminimalisasi dampak bencana gempa bumi yang akan terjadi dimasa datang.

\section{Metodologi Penelitian}

Pengolahan menggunakan metode PSHA dilakukan dengan bantuan software Ez-Frisk 7.52. Analisis seismik hazard dengan menggunakan metode PSHA dilalukan melalui beberapa tahap, yaitu:

a. Pengumpulan data gempa

Data gempabumi selama 115 tahun pada koordinat $-6,33^{\circ}$ LS sampai $-11,33^{\circ}$ LS dan $112,45^{\circ}$ BT sampai $119,83^{\circ} \mathrm{BT}$ diperoleh dari katalog gempabumi USGS, ISC dan ANSS. Data yang digunakan berupa kedalaman maksimum $300 \mathrm{~km}$ dan magnitudo $\geq 5 \mathrm{Mw}$.

b. Konversi skala magnitudo

Adanya perbedaan skala magnitudo mengharuskan penggunaan suatu metode sebagai acuan dalam menyamakan skala menjadi satu skala yang sama sebelum digunakan dalam analisis resiko gempa. Dalam penelitian ini, skala magnitudo dikonversikan kedalam skala magnitudo momen (moment magnitude, $M_{w}$ ) [8].

c. Identifikasi gempabumi

Proses identifikasi gempabumi dilakukan dengan memisahkan antara gempa utama dengan gempa susulan terhadap data rekaman berdasarkan kriteria rentang waktu dan jarak (declustering). Kriteria untuk mengidentifikasi gempabumi telah diteliti oleh Gardner dan Knopoof [5]. Pemisahan gempabumi utama dibantu menggunakan software ZMAP [10].

d. Pemodelan Sumber Gempa

Pemodelan sumber gempa dalam penelitian ini berdasarkan sumber gempa subduksi dan background.Sumber gempa subduksi adalah model yang didapat dari data seismotektonik yang sudah teridentifikasi. Batas kedalaman dimodelkan hingga $50 \mathrm{~km}$ (megathrust). Sumber gempa background merupakan zona gempa diluar zona sesar dan megathrust. Pemodelan gempa background merupakan pemodelan gempa yang digunakan untuk memprediksi gempabumi pada suatu daerah yang belum banyak dijumpai data seismiknya akan tetapi pernah terjadi gempa di daerah itu. Pemodelan untuk sumber gempa background menggunakan model gridded seismicity.

e. Penentuan Parameter $a$ dan $b$

Parameter $a$ dan $b$ merupakan parameter yang digunakan untuk memprediksi nilai maksimum gempa dari sumber gempa. Parameter ini ditentukan dengan menggunakan metode maximum likelihood[1] dengan bantuan softwareZMAP.

\section{f. Fungsi Atenuasi}

Fungsi atenuasi didasarkan pada kesamaan kondisi geologi suatu tempat dan kondisi tektoniknya. Wilayah Indonesia belum ada data yang digunakan untuk menurunkan fungsi atenuasi, sehingga diperlukan data dari wilayah lain yang memiliki kemiripan sifat geologi dan seismotektonik dengan wilayah yang akan diteliti di Indonesia.Pemilihan fungsi atenuasi disesuaikan pada mekanisme sumber gempa yang sudah di modelkan. Fungsi atenuasi yang digunakan dalam penelitian ini dapat dilihat pada Tabel 1 . 
Tabel 1. Fungsi atenuasi untuk model sumber gempa [2]

\begin{tabular}{|l|l|}
\hline \multicolumn{1}{|c|}{ Sumber Gempa } & \multicolumn{1}{|c|}{ Fungsi Atenuasi } \\
\cline { 2 - 2 } $\begin{array}{l}\text { Subduksi interface } \\
\text { (megathrust) }\end{array}$ & Youngs et al \\
\cline { 2 - 2 } & Zhao et al \\
\cline { 2 - 2 } & Atkinson-Boore, Worldwide \\
\hline \multirow{2}{*}{$\begin{array}{l}\text { Subduksi intraslab } \\
\text { (benioff) }\end{array}$} & Atkinson-Boore, Worldwide \\
\cline { 2 - 2 } & Atkinson-Boore, Cascadia \\
\cline { 2 - 2 } & Youngs et al \\
\hline \multirow{2}{*}{$\begin{array}{l}\text { Sesar\& } \\
\text { shallow } \\
\text { background }\end{array}$} & Campbell-Bozorgnia, NGA \\
\cline { 2 - 2 } & Boore-Atkinson, NGA \\
\cline { 2 - 2 } & Chiou -Youngs, NGA \\
\hline
\end{tabular}

g. Probabilistic Seismic Hazard Analysis Metode PSHA memberikan ruang kerja yang memungkinkan faktor ketidakpastian dapat diidentifikasi, diukur dan digabungkan pada suatu hubungan yang rasional untuk menghasilkan gambaran yang lebih rinci dalam perhitungan risiko gempa [6]. PSHA dilakukan untuk mengetahui risiko tingkat gerakan tanah secara kuantitatif dengan berdasar pada teorema probabilitas total. Teori probabilitas totalmengasumsikan magnitudo $M$ dan jarak $R$ sebagai variabel acak independen yang menerus [3], dapat dinyatakan sebagai berikut

$P[I \geq i]=\iint r m P[I \geq i \mid m$ dan $r] f M(m) f R(r)$ $\mathrm{dm} \mathrm{dr}$

dengan fM adalah fungsi distribusi dari magnitude, $\mathrm{fR}$ adalah fungsi distribusi dari jarak hiposenter dan $\mathrm{P}[\mathrm{I} \geq \mathrm{i} \mid \mathrm{m}$ dan $\mathrm{r}]$ adalah probabilitas bersyarat dari intensitas I yang melampaui nilai I pada suatu lokasi yang ditinjau untuk kejadian gempa dengan magnitudo $\mathrm{M}$ dan jarak $\mathrm{R}$. h. Diagram Alir Penelitian

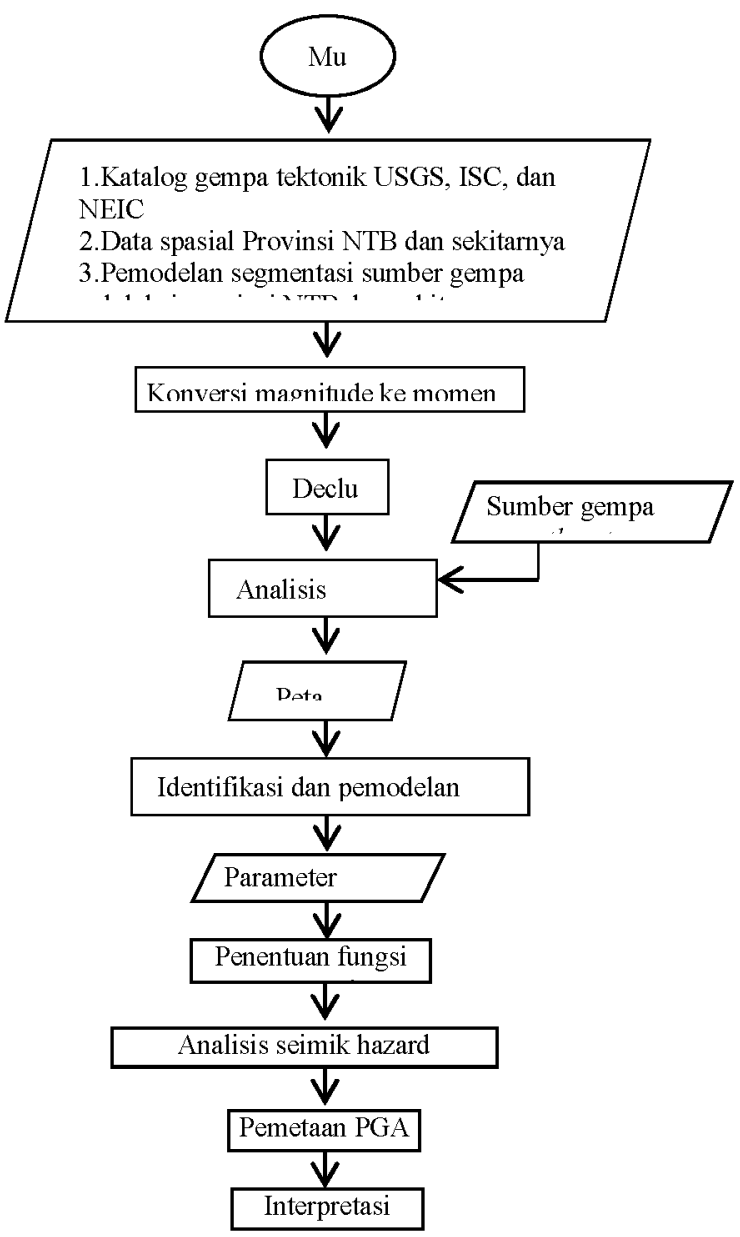

2. Hasil dan Pembahasan

Hazard dikaitkan dengan salah satu parameter ground motion yaitu percepatan getaran di batuan dasar (Peak Ground Acceleration dan Spectral Acceleration). Percepatan yang ditimbulkan oleh gempa dengan periode ulang tertentu sebagai representasi hazard yang mungkin terjadi di suatu lokasi dengan asumsi bahwa percepatan pada lokasi penelitian memiliki distribusi poisson dengan laju tahunan ratarata (annual of rate exceedance). Nilai PGA dan SA dalam metode PSHA diperoleh dari rumusan hubungan prediksi gerakan tanah atau yang sering disebut fungsi atenuasi. 
Peta hazard gempa bumi merupakan gambaran secara regional mengenai potensi risiko pada daerah penelitian. Nilai seismic hazard ditampilkan sebagai kontur PGA dan SA di batuan dasar yang diperkirakan terlampaui $10 \%$ dan $2 \%$ dalam 50 tahun yang di timbulkan oleh berbagai mekanisme sumber gempa. Peta yang dihasilkan pada penelitian ini yaitu peta hazard dari berbagai mekanisme sumber gempa, yaitu sumber gempa subduksi dan background.

a. Peta Hazard Untuk Sumber Gempa Subduksi

Nilai PGA tinggi terletak pada Propinsi Nusa Tenggara Barat bagianselatan yang merupakan daerah yang dekat dengan zona subduksi Sumba. Hal ini menunjukkan wilayah Nusa Tenggara Barat dominan dipengaruhi oleh sumber-sumber gempa yang dihasilkan oleh subduksi lempeng Indo-Australia yang menunjam ke bawah lempeng Eurasia sekitar 50-70 $\mathrm{mm}$ /tahun.Sebaran nilai PGA di Propinsi Nusa Tenggara Barat untuk periode ulang 500 tahun (Gambar 1) berkisar antara 0.05 $\mathrm{g}-0.1 \mathrm{~g}$, sedangkan untuk periode ulang 2500 tahun (Gambar 2) adalah $0.08 \mathrm{~g}-0.3$ $\mathrm{g}$.

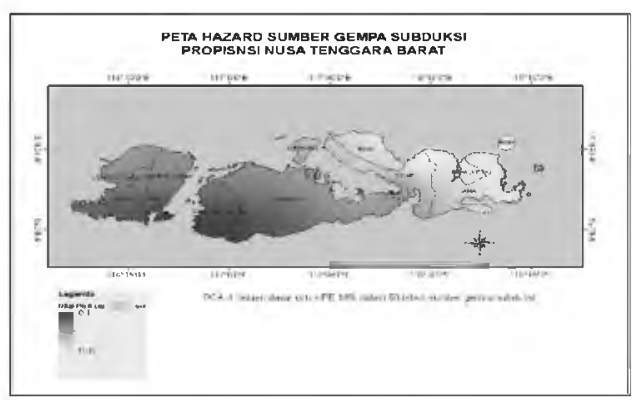

Gambar 2. Peta hazard sumber gempa subduksi dengan PGA batuan dasar untuk periode ulang 500 tahun

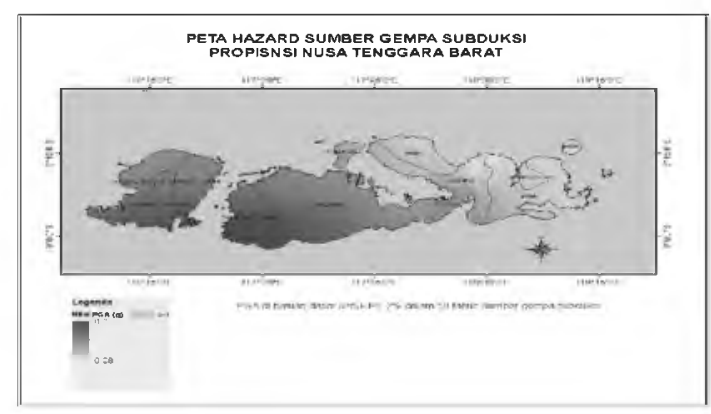

Gambar 3. Peta hazard sumber gempa subduksi dengan PGA batuan dasar untuk periode ulang 2500 tahun

b. Peta Hazard Untuk Sumber Gempa Shallow Background

Berdasarkan peta hazard untuk sumber gempa shallow background, nilai PGA tinggi terdapat pada bagian timur laut Propinsi Nusa Tenggara Barat. Hal ini dikarenakan pada daerah tersebut banyak terdapat titik-titik kegempaan dangkal di luar zona megathrust dan sesar namun belum teridentifikasi dengan jelas mekanisme dan geometri sesarnya. Sebaran nilai PGA di Propinsi Nusa Tenggara Barat untuk periode ulang 500 tahun (Gambar 3) berkisar antara $0.1 \mathrm{~g}-0.3 \mathrm{~g}$, sedangkan untuk periode ulang 2500 tahun (Gambar 4) adalah $0.2 \mathrm{~g}-0.5 \mathrm{~g}$.

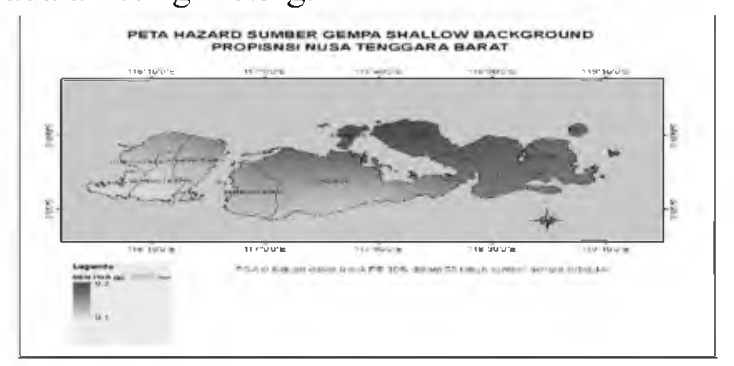

Gambar 4. Peta hazard sumber gempa shallow background dengan PGA batuan dasar untuk periode ulang 500 tahun

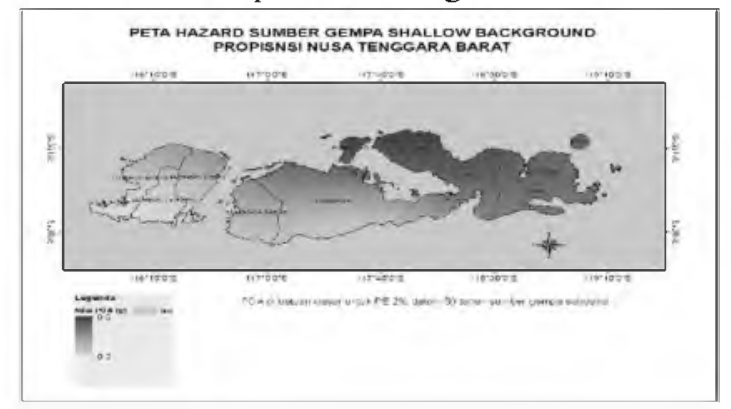

Gambar 5. Peta hazard sumber gempa shallow background dengan PGA batuan dasar untuk periode ulang 2500 tahun

\section{c. Peta Hazard Untuk Sumber Gempa Deep Background \\ Berdasarkan peta hazard untuk} sumber gempa deep background pada Gambar 4.7 dan Gambar 4.8, nilai PGA tinggi terdapat pada wilayah bagian selatan Propinsi Nusa Tenggara Barat. Sebaran nilai PGA di Propinsi Nusa Tenggara Barat 
untuk periode ulang 500 tahun (Gambar 5) berkisar antara $0.2 \mathrm{~g}-0.3 \mathrm{~g}$, sedangkan untuk periode ulang 2500 tahun (Gambar 6) adalah $0.3 \mathrm{~g}-0.4 \mathrm{~g}$.

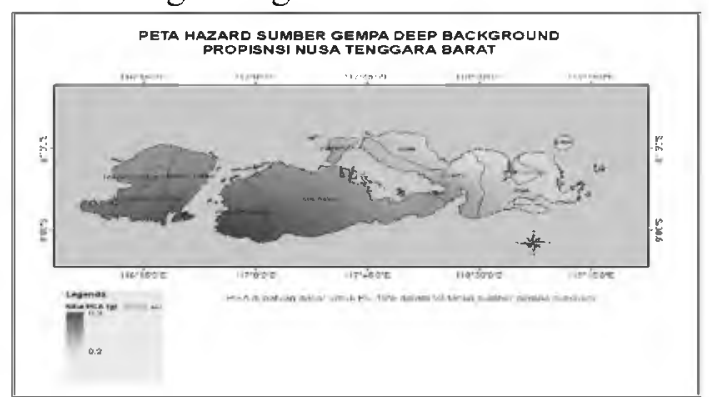

Gambar 6 Peta hazard sumber gempa deep background dengan PGA batuan dasar untuk periode ulang 500 tahun

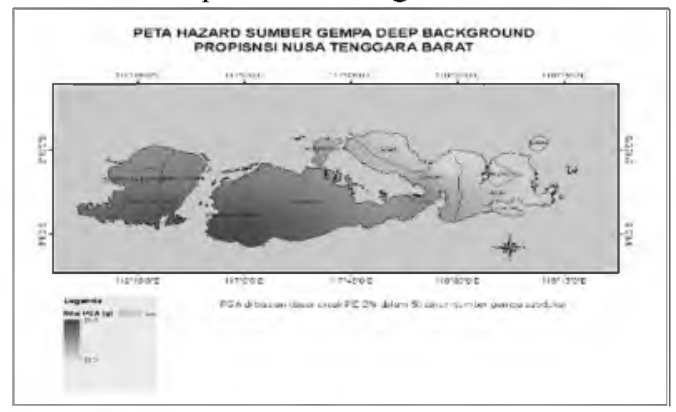

Gambar 7. Peta hazard sumber gempa deep background dengan PGA batuan dasar untuk periode ulang 2500 tahun

3. Kesimpulan

1. Hasil percepatan spektra akibat sumber gempa subduksi di Propinsi Nusa Tenggara Barat berdasarkan analisis probabilistik berkisar antara $0.04 \mathrm{~g}-$ $0.1 \mathrm{~g}$ untuk periode ulang 500 tahun, sedangkan untuk periode ulang 2500 tahun adalah $0.08 \mathrm{~g}-0.3 \mathrm{~g}$.

2. Hasil percepatan spektra akibat sumber gempa shallow background di Propinsi Nusa Tenggara Barat berdasarkan analisis probabilistik berkisar antara 0.1 $\mathrm{g}-0.3 \mathrm{~g}$ untuk periode ulang 500 tahun, sedangkan untuk periode ulang 2500 tahun adalah $0.2 \mathrm{~g}-0.5 \mathrm{~g}$.

3. Hasil percepatan spektra akibat sumber gempa deep background di Propinsi Nusa Tenggara Barat berdasarkan analisis probabilistik berkisar antara 0.2 $\mathrm{g}-0.3$ guntuk periode ulang 500 tahun, sedangkan untuk periode ulang 2500 tahun adalah $0.3 \mathrm{~g}-0.4 \mathrm{~g}$.
4. Saran

Perlu dilakukan pemodelan sumber gempa sesar dengan mengakomodir sumber sesar aktif di daerah Nusa Tenggara Barat.

\section{Ucapan Terimakasih.}

Penulis mengucapkan terima kasih kepada Sekolah Tinggi Teknologi Adisutjipto Yogyakarta yang telah memberi dukungan financial terhadap penelitian ini

\section{DAFTAR PUSTAKA}

[1] Aki, K., 1965, Maximum Likelihood Estimate of $b$ value in the Formula $\log \mathrm{N}=\mathrm{a}-\mathrm{bM}$ and Its Confidence Limits. Bulletin of Earthquake, Res. Ins., Tokyo University.

[2] Asrurifak M., 2010, Peta Respon Spektra Indonesia Untuk Perencanaan Struktur Bangunan Tahan Gempa Dengan Model Sumber Gempa Tiga Dimensi Dalam Analisa Probabilitas, Disertasi, Teknik Sipil Institut Teknologi Bandung.

[3] Cornell, A.C., 1968, Engineering seismic risk analysis, Bulletin of the Seismological Society of America, October 1968, v. 58, no. 5, p. 1583-1606.

[4] Daryono, 2011, Indeks Kerentanan Seismik Berdasarkan Mikrotremor pada Setiap Bentuklahan di Zona Graben Bantul, Daerah Istimewa Yogyakarta. Disertasi, Program Pascasarjana Fakultas Geografi UGM, Yogyakarta.

[5] Gardner, J. K. dan Knopoff, L., 1974, Is the sequence of earthquakes in southern California, with aftershocks removed, Poissonian?, Bulletin of the Seismological Society of America 64, 1,363-1,367

[6] Irsyam, M., Sengara I.W., Adiamar, F., Widiyantoro, S., Triyoso, W., Natawidjaja, D.H., [7] Kertapati, E., Meilano, I., Suhardjono, Asrurifak, M., dan 
Ridwan, M., 2010, Ringkasan Hasil Studi Tim Revisi Peta Gempa Indonesia, Bandung. Kramer, S.L., 1996, Geotechnical Earthquake Engineering, Prentice Hall, New Jersey.

[8] Pasau, G., dan Tanauma, A., 2011, Pemodelan Sumber Gempa di Wilayah Sulawesi Utara Sebagai Upaya Mitigasi Bencana Gempa bumi, Jurnal Ilmiah Sains Vol. 11 No. 2, Oktober 2011.

[9] Sunardi, Bambang, 2009, Analisa Fraktal dan Rasio Slip Daerah Bali-NTB Berdasarkan Pemetaan Variasi Parameter Tektonik, Jurnal Meteorologi dan Geofisika 10,1, 58-65.

[10] Wiemer, S., 2001, A software package to analyze seismicity: ZMAP, Seismological Research Letter, 72(2): 373-382. 